\title{
Pneumatosis coli as a rare complication of bowel preparation
}

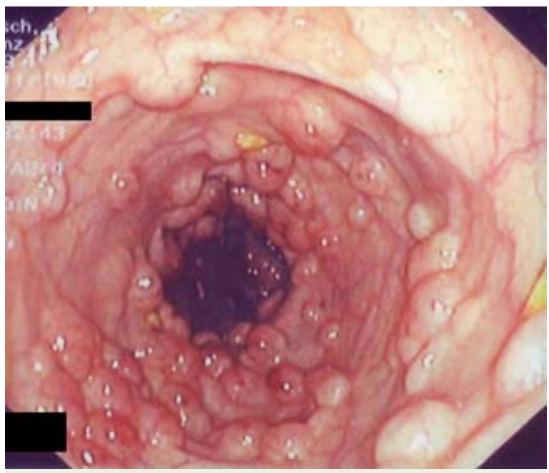

Fig. 1 Numerous (> 50) close standing polyps in the sigmoid over a total distance of $20 \mathrm{~cm}$.

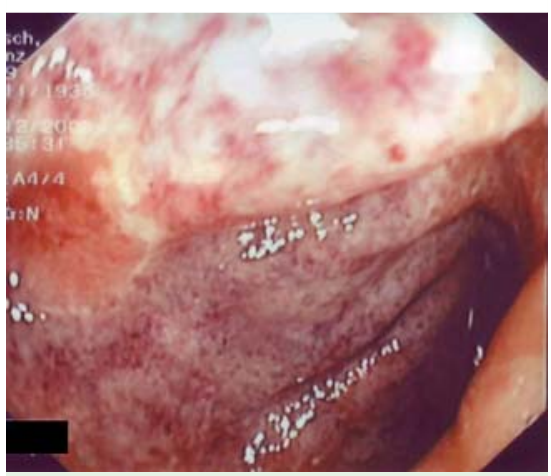

Fig. 2 Segmental erosive-ulcerative mucosal damage with punctuate hemorrhages and a deep-blue appearing mucosa in the descending colon.

Intestinal lavage for colonoscopy is a safe procedure, even in elderly patients [1]. This is the first report describing a case of acute ischemic colitis with pneumatosis coli resulting from bowel preparation in a patient with anatomic predispositions.

A 69-year-old man was admitted for screening colonoscopy. His medical history was not significant. A formulation of polyethylene glycol and electrolytes was used for lavage. Physical examination and laboratory tests were unremarkable prior to endoscopy. Endoscopically, the sigmoid exhibited numerous (>50) close standing polyps ( $\bullet$ Fig. 1 ).

The descending colon showed a segmental, erosive-ulcerative colitis ( $\mathbf{F i g}$. 2).

In the transverse colon a subtotal stenosis could not be passed. Histopathologic examination revealed acute colonic ischemia in the descending colon ( $\bullet$ Fig. 3 )

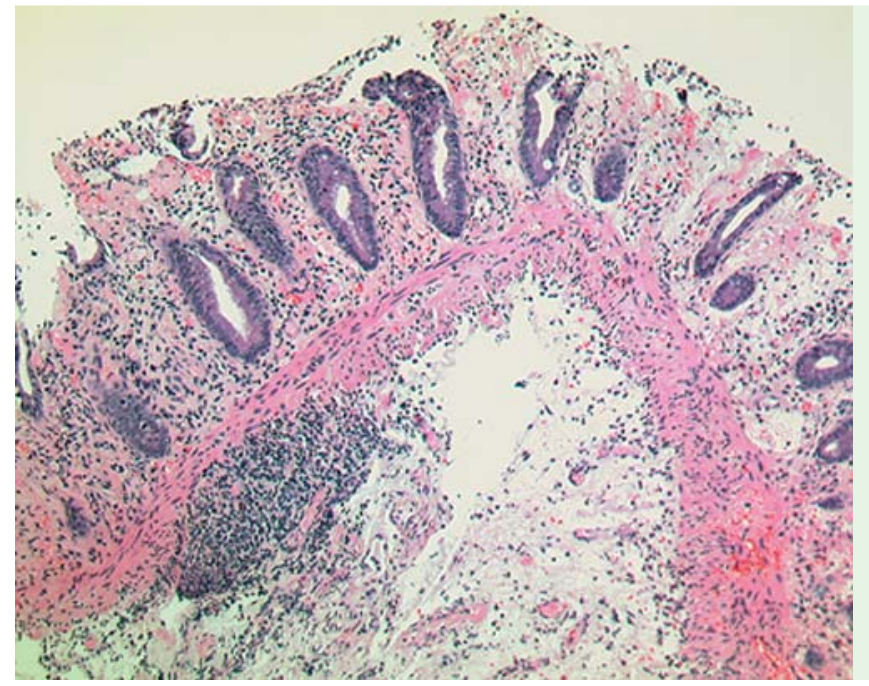

Fig. 3 Histopathologic examination of the descending colon showing necrotic mucosa with fibrinous exudates containing neutrophil granulocytes and capillary microthrombi, confirming acute colonic ischemia.

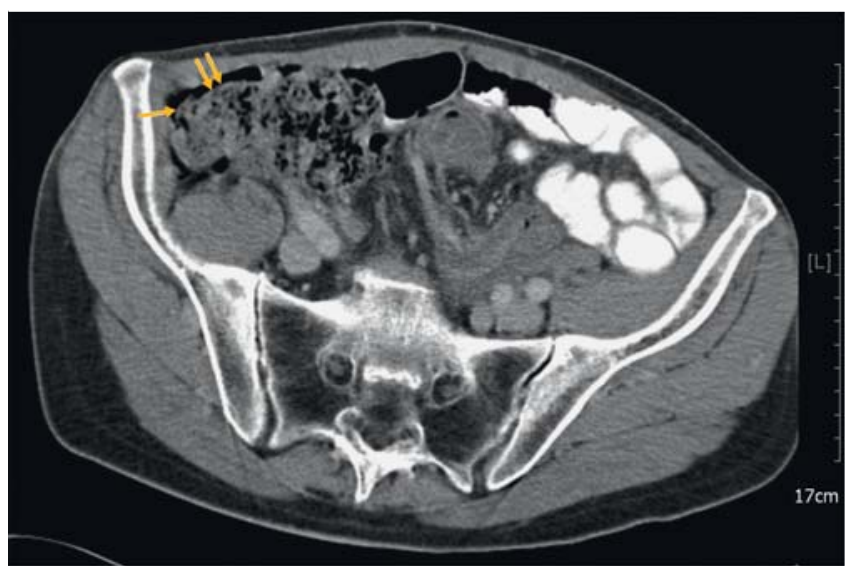

Fig. 4 Bubblelike pneumatosis intestinalis in the sigmoid (arrows).

and discrete crypt architectural distortion in the polypoid lesions.

Specific etiologies of ischemic colitis [2] were excluded in a thorough workup. Computed tomography (CT) showed a considerably elongated sigmoid with bubblelike pneumatosis coli ( $\bullet$ Fig. 4 ) and a circular thickening of the transverse colon. Mesenteric angiography revealed markedly rarefied colonic arteries with small caliber, but no advanced atherosclerosis (๑ Fig. 5).

Double-contrast barium enema revealed an extensive dolichocolon with formation of a loop at the splenic flexure ( $\bullet$ Fig. 6 ). About $15 \%$ of cases of colonic ischemia develop potentially life-threatening gangrene [3] and pneumatosis has been considered as an indicator of advanced ische- mia [2]. Recent evidence suggests, however, that isolated pneumatosis does not always indicate transmural infarction [4]. In our case, the patient completely recovered and subsequent complete colonoscopies revealed no signs of ischemia. The ischemic colitis most likely resulted from a combination of enhanced colonic viability and the associated demand of increased perfusion during intestinal lavage on the one hand, and a limited perfusion reserve due to the extensive dolichocolon with rarified visceral arteries on the other hand. This case further exemplifies that isolated pneumatosis is not necessarily associated with transmural infarction.

\section{Competing interests: None}



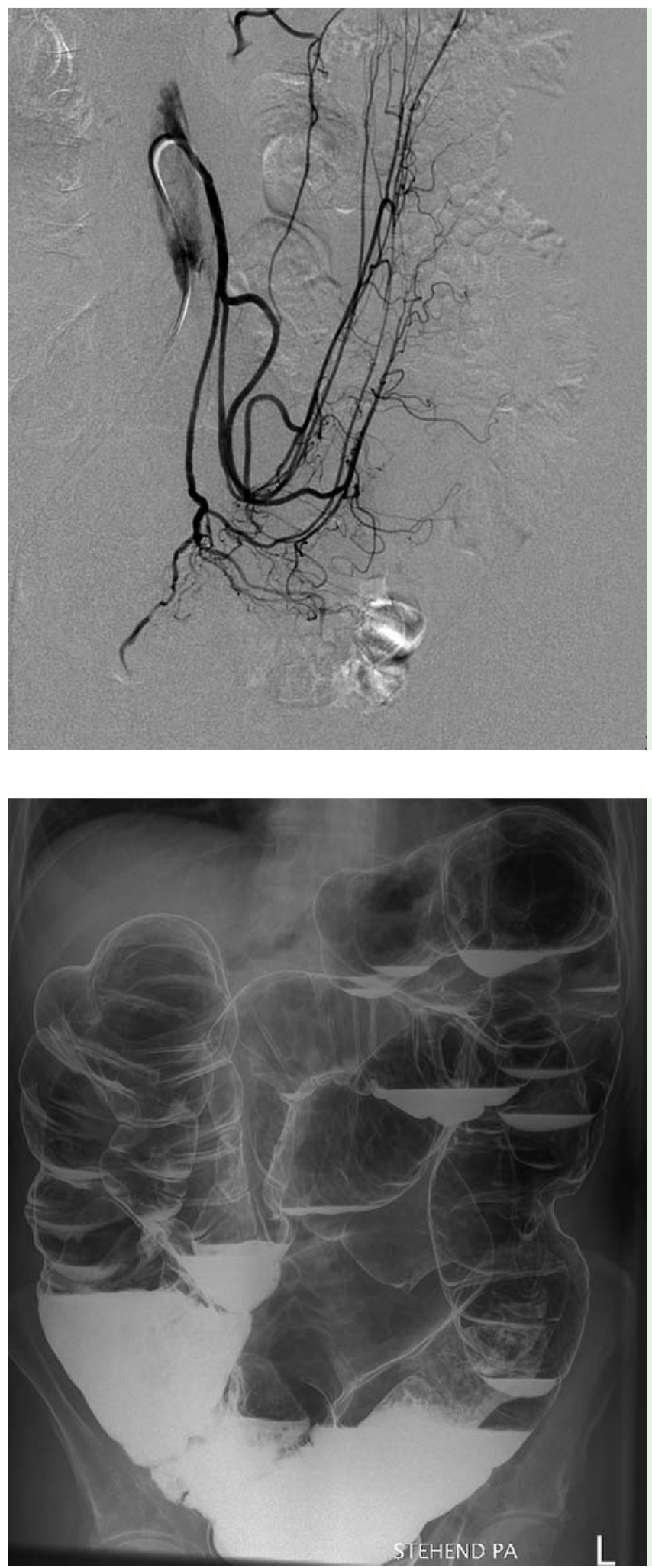

Fig. 5 Mesenteric angiography revealed markedly rarefied and small-caliber visceral arteries in the colon.

Endoscopy_UCTN_Code_CPL_1AJ_2AI

\section{T. Rath, E. Roeb, W. E. Doppl}

Department of Internal Medicine, Division of Gastroenterology,

Justus-Liebig-University, Giessen, Germany

\section{References}

1 Clarke GA, Jacobson BC, Hammett RF, CarrLocke $D L$. The indications, utilization and safety of gastrointestinal endoscopy in an extremely elderly patient cohort. Endoscopy 2001; 33: 580-584

2 Brandt LJ, Boley SJ. AGA technical review on intestinal ischemia. American Gastrointestinal Association. Gastroenterology 2000; 118: 954-968

3 Elder K, Lashner BA, Al Solaiman F. Clinical approach to colonic ischemia. Cleve Clin J Med 2009; 76: 401 - 409

4 Kernagis LY, Levine MS, Jacobs JE. Pneumatosis intestinalis in patients with ischemia: correlation of CT findings with viability of the bowel. AJR Am J Roentgenol 2003; 180: $733-736$

\section{Bibliography}

DOI $10.1055 / \mathrm{s}-0030-1255977$

Endoscopy 2010; 42: E344-E345

(c) Georg Thieme Verlag KG Stuttgart · New York . ISSN 0013-726X

Fig. 6 Double-contrast barium enema showing extensive dolichocolon with formation of a loop at the splenic flexure.

\section{Corresponding author}

\section{Professor E. Roeb}

Justus-Liebig-University

Gastroenterology

Paul-Meimberg-Str. 5

35385 Giessen

Germany

Fax: +49-641-9942339

elke.roeb@innere.med.uni-giessen.de 